\title{
RSI-maatregelen in de Nederlandse beroepsbevolking
}

\author{
J. Heinrich • B.M. Blatter • S.N.J. van den Bossche • P.G. \\ W. Smulders
}

Samenvatting Het doel van de huidige studie is inzicht geven in het vóórkomen van verschillende RSI-maatrege-len in Nederland in 2003. Het onderzoek is uitgevoerd met gegevens uit de Nationale Enquête Arbeidsomstandigheden (NEA), een cross-sectioneel vragenlijstonderzoek bij een aselecte steekproef van 25.000 werknemers. De vragenlijst bevatte vier vragen over RSI-maatregelen.

De maatregelen 'inrichting van de werkplek' en 'voorlichting' werden het meest toegepast, respectievelijk $35 \%$ en $24 \%$. 'Aanpassing van werk- of pauzetijden' en 'verandering van takenpakket' zijn maatregelen die veel minder werden toegepast, respectievelijk bij $8 \%$ en $3 \%$ van de werknemers. Ondanks dat er al wel RSI-maatregelen werden genomen, bestond er nog wel behoefte aan RSImaatregelen.Werknemers hadden het meest behoefte aan 'inrichting van de werkplek' $(21 \%)$. Tussen sectoren waren duidelijke verschillen in RSI-maatregelen die al toegepast werden en RSI-maatregelen waar nog behoefte aan was. Deze verschillen zijn mogelijkerwijs te verklaren door afgesloten arboconvenanten.

Keywords RSI-maatregelen · arboconvenanten · RSIklachten

\footnotetext{
J. Heinrich $(\bowtie)$

Belangenconflicten: geen gemeld Financiële ondersteuning: ministerie van Sociale Zaken en WerkgelegenheidPersonaliaJ. Heinrich, B.M. Blatter, S.N.J. van den Bossche enP.G.W. Smulders werken bij TNO Arbeid te Hoofddorp;B.M. Blatter werkt ook bij Body@Work, Onderzoekscentrum Bewegen, Arbeid en Gezondheid, TNO VUmc.CorrespondentieadresJ. Heinrich, TNO Arbeid, Postbus 718, 2130 AS Hoofddorp Email: j.heinrich@arbeid.tno.nl.
}

\section{Inleiding}

Uit vragenlijstonderzoek blijkt dat in $200228 \%$ van de Nederlandse beroepsbevolking in de voorafgaande 12 maanden last heeft gehad van werkgerelateerde klachten aan nek, schouders, armen/ellebogen of polsen/ handen. ${ }^{1}$ Deze (a)specifieke klachten worden regelmatig samengevat onder het containerbegrip RSI, hoewel ook andere benamingen zijn geopperd. In dit artikel hanteren we de term RSI omdat deze term het meest bekend is, in de vragenlijst is gebruikt en ook in de arboconvenanten gehanteerd wordt. RSI-klachten vormen een belangrijk probleem, omdat ze naast pijn en beperkingen bij de werknemer kunnen leiden tot bedrijfsmatige en maatschappelijke kosten. De overheid vindt het belangrijk om RSI-klachten te reduceren. Om hierin een sturende rol te kunnen vervullen heeft de overheid 'arboconvenanten nieuwe stijl' ontwikkeld. ${ }^{2}$ Arboconvenanten zijn afspraken tussen werkgevers, werknemers en de overheid teneinde streefcijfers te kunnen realiseren voor bijvoorbeeld de prevalentie van RSI-klachten.

De overheid sluit deze arboconvenanten af met werkgevers en werknemers binnen hoog-risico-sectoren en sectoren die zichzelf melden. Vervolgens worden afspraken gemaakt over maatregelen. Vanaf 2001 zijn verschillende arboconvenanten afgesloten waarin afspraken zijn gemaakt over RSI-maatrege-len, namelijk voor de sectoren: Bankwezen, Architecten, Uitgeverijen, Provincies, Zorgverzekeraars, Rijksoverheid, Gemeenten, Grafimedia, Woningcorporaties, Schoonmaak, Vleesindustrie, Sociale Werkvoorziening, Kappers, Ziekenhuizen en Academische ziekenhuizen. Al deze sectoren samen betreffen ongeveer 1.194.000 werknemers.

Om RSI-klachten zo efficiënt mogelijk terug te kunnen dringen is het belangrijk te weten welke RSI- 
maatregelen effectief zijn. Om hier uitspraken over te kunnen doen zijn omvangrijke, en daardoor kostbare, studies noodzakelijk. Helaas zijn tot nog toe weinig van deze studies uitgevoerd. ${ }^{3}$ De huidige studie is vanwege de cross-sectionele opzet niet geschikt voor dit doel. Naast kennis over de effectiviteit van maatregelen is het belangrijk om informatie te hebben over de implementatie van maatregelen. Hierdoor wordt namelijk inzicht verkregen over de beroepsgroepen waar nog extra aandacht aan moet worden besteed, de behoefte aan het soort maatregelen (binnen verschillende beroepsgroepen), de uitvoerbaarheid van het soort maatregelen en de mogelijke invloed van arboconvenanten. Het doel van de huidige studie is om inzicht te geven in het vóórkomen van verschillende RSI-maatregelen in Nederland in 2003. De volgende vragen worden in dit artikel beantwoord:

1. Bij hoeveel werknemers werden in 2003 de RSI-maatregelen 'voorlichting', 'verandering van takenpakket', 'aanpassing van werk- of pauzetijden' en 'aanpassing van werkplekinrichting' toegepast?

2. Aan welke RSI-maatregelen die nog niet werden toegepast, hadden werknemers in 2003 behoefte?

3. Zijn er in relatie tot de genomen en gewenste RSImaatregelen verschillen waar te nemen tussen beroeps- en bedrijfscategorieën?

1. In 2003 werden binnen de Nederlandse werknemerspopulatie de RSI-maatregelen 'voorlichting over RSI' en 'aanpassing van de inrichting van de werkplek' het meest toegepast.

2. Werknemers hadden het meest behoefte aan aanpassing van de inrichting van hun werkplek.

3. Tussen sectoren waren duidelijke verschillen in RSI-maatregelen die al toegepast werden en RSI-maatregelen waar nog behoefte aan was. Deze verschillen zijn mogelijkerwijs te verklaren door afgesloten arboconvenanten.

\section{Methode}

Populatie en vragenlijst

Voor dit onderzoek is gebruik gemaakt van de eerste Nationale Enquête Arbeidsomstandigheden (NEA) in 2003. De NEA is een vragenlijstonderzoek om ontwikkelingen op het gebied van arbeid en arbeidsomstandigheden te kunnen monitoren. Elke twee jaar wordt er een nieuwe steekproef van 25.000 werknemers getrokken die de vragenlijst krijgt thuisgestuurd. De NEA zelf heeft dus een herhaaldelijk karakter, maar er worden geen werknemers gevolgd in de tijd. Omdat bij een steekproeftrekking het risico op selectiviteit vanwege non-respons niet volledig valt uit te sluiten, zijn de data uit de NEA gestandaardiseerd voor geslacht, bedrijfstak, leeftijd en opleidingsniveau. Hierdoor was sprake van cijfers die representatief zijn voor de Nederlandse werknemerspopulatie. De vragenlijst bevatte vragen over diverse aspecten zoals dienstverband, beroep en bedrijfstak, psychosociale belasting, aandoeningen en ziekten en arbomaatregelen. ${ }^{4}$

\section{Operationalisatie van RSI-maatregelen}

Uit een breed scala aan RSI-maatregelen is bij het opstellen van de vragenlijst een keuze gemaakt voor vier veel voorkomende maatregelen. Sommige maatregelen kunnen bedrijfsbreed worden ingezet, andere specifiek per werknemer. In de vragenlijst kwamen de volgende vier vragen aan de orde:

1. Heeft $u$ voorlichting gekregen over RSI en wat $u$ kunt doen om de kans op RSI te verminderen?

2. Is uw takenpakket veranderd om de kans op RSI te verminderen?

3. Zijn uw werk- of pauzetijden aangepast om de kans op RSI te verminderen?

4. Is de inrichting van uw werkplek aangepast aan uw lengte of uw taken, zodat $\mathrm{u}$ in een goede werkhouding kunt werken?

Alle vragen konden worden beantwoord met 'ja', 'nee, maar ook niet nodig' of 'nee, maar is wel behoefte aan'. Doordat de vier vragen onderling redelijk met elkaar samenhingen hebben de vragen enige herhaling in zich.

\section{Variabelen voor subanalyses}

De keuze om maatregelen wel of niet te implementeren wordt beïnvloed door verschillende factoren. Zo kunnen bedrijfsgrootte, het soort werkzaamheden en het aantal werknemers met RSI-klachten voor een bedrijf van invloed zijn. Bij de resultaten is daarom een onderverdeling gemaakt naar bedrijfsgrootte, kantoorwerkers en werknemers met en zonder RSI-klachten. Bovendien zijn de resultaten per beroeps- en bedrijfscategorie weergegeven.

Bedrijfsgrootte is geoperationaliseerd door kleine bedrijven (1-99 werknemers) en grote bedrijven $(\geq 100$ werknemers) te onderscheiden. We hebben een criterium van 100 werknemers gekozen, omdat de ervaring leert dat vooral bedrijven met meer dan 100 werknemers RSImaatregelen toepassen. Voor de deelpopulatie kantoorwerkers zijn in eerste instantie beroepscategorieën geselecteerd die zeker tot de kantoorwerkers behoren. Daarna zijn uit de beroepscategorieën die waarschijnlijk een groot aantal kantoorwerkers bevatten, werknemers geselecteerd die voor hun werk ten minste 3 uur per dag beeldschermwerk verrichten. Voor het vaststellen van 
RSI-klachten zijn 12 vragen gesteld over mogelijke klachten in de nek, schouders, armen, polsen, handen en/of vingers die men in de afgelopen 3 maanden had. Per vraag konden werknemers antwoorden met 'altijd', 'vaak', 'soms' of 'nooit'. Iemand met 8 of meer punten (maximaal 36 punten) had last (gehad) van RSIklachten. ${ }^{5}$

\section{Analyse}

Om inzicht te geven in het vóórkomen van maatregelen zijn beschrijvende analyses uitgevoerd en percentages gepresenteerd. Vanwege de grootte van de onderzoekspopulatie waren ook relatief kleine verschillen in percentages in tabel 1 statistisch significant. Daarom hebben we in tabel 1 alleen de relevante verschillen gemarkeerd. Hiervoor hebben we het absolute verschil in percentage tussen subgroepen gerelateerd aan het totaal percentage binnen de desbetreffende antwoordcategorie. Wij beschouwden een verschil relevant als het absolute verschil gelijk aan of groter is dan $1 / 3$ van het totaal percentage.

Bij de uitsplitsing van gegevens naar beroeps- en bedrijfscategorieën (tabel 2 en 3) zijn alleen categorieën gepresenteerd die ten minste 50 respondenten bevatten. Om statistisch significante verschillen $(p<0,05)$ in percentages tussen specifieke beroeps- en bedrijfscategorieën en de totale onderzoeks-populatie aan te kunnen tonen is de chikwadraattoets toegepast.

\section{Resultaten}

Populatiekenmerken

De respons bedroeg $42 \%$ en daarmee bestond de onderzoekspopulatie uit 10.075 werknemers. Van de onderzoekspopulatie werkte $42 \%$ bij een groot bedrijf en behoorde $44 \%$ tot onze definitie van kantoorwerker. In totaal had $25 \%$ van de onderzoekspopulatie in de afgelopen 3 maanden RSI-klachten.

\section{RSI-maatregelen}

In tabel 1 is aangegeven bij hoeveel werknemers in 2003 RSI-maatregelen werden toegepast en aan welke maatregelen behoefte was. De maatregelen 'inrichting van de werkplek' en 'voorlichting' werden het meest toegepast, respectievelijk bij $35 \%$ en $24 \%$ van alle werknemers. 'Aanpassing van werk- of pauzetijden' $(8 \%)$ en 'verandering van takenpakket' (3\%) werden veel minder

Tabel 1 Getroffen en al dan niet gewenste RSI-maatregelen in 2003. Totale onderzoekspopulatie en subgroepen voor kleine/grote bedrijven, kantoorwerkers/niet-kantoorwerkers en werknemers met/zonder RSI-klachten: percentage werknemers per categorie

\begin{tabular}{|c|c|c|c|c|c|c|c|c|}
\hline \multirow{2}{*}{\multicolumn{2}{|c|}{ Maatregel }} & \multirow{2}{*}{$\begin{array}{l}\text { Totaal } \\
(\mathrm{n}= \\
9933)\end{array}$} & \multirow{2}{*}{$\begin{array}{r}\text { Bedrijfsgrootte } \\
\text { Groot } \\
(\mathrm{n}=4126)\end{array}$} & \multirow[b]{2}{*}{$\begin{array}{l}\text { Klein } \\
(\mathrm{n}= \\
5747)\end{array}$} & \multicolumn{2}{|c|}{ Kantoorwerkers } & \multicolumn{2}{|c|}{ RSI-klachten } \\
\hline & & & & & $\begin{array}{c}\text { Ja } \\
(\mathrm{n}= \\
4343)\end{array}$ & $\begin{array}{l}\text { Nee } \\
(\mathrm{n}= \\
5433)\end{array}$ & $\begin{array}{r}\text { Ja } \\
(\mathrm{n}= \\
2515)\end{array}$ & $\begin{array}{l}\text { Nee } \\
(\mathrm{n}= \\
7413) \\
\end{array}$ \\
\hline \multicolumn{9}{|l|}{$\overline{\text { Voorlichting over RSI? }}$} \\
\hline $\mathrm{Ja}$ & & 24 & 36 & $16 \#$ & 44 & $9 \#$ & 22 & 25 \\
\hline Nee, maar is ook niet nodig & & 58 & 45 & $66 \#$ & 32 & $78 \#$ & 50 & 60 \\
\hline Nee, maar is wel behoefte aan & & 18 & 18 & 18 & 24 & $13 \#$ & 29 & $15 \#$ \\
\hline \multicolumn{9}{|c|}{$\begin{array}{l}\text { Takenpakket veranderd om kans op RSI te } \\
\text { verminderen? }\end{array}$} \\
\hline $\mathrm{Ja}$ & & 3 & 4 & $2 \#$ & 4 & $2 \#$ & 4 & $3 \#$ \\
\hline Nee, maar is ook niet nodig & & 83 & 81 & 84 & 76 & 88 & 70 & 87 \\
\hline Nee, maar is wel behoefte aan & & 14 & 15 & 14 & 20 & $10 \#$ & 27 & $10 \#$ \\
\hline \multicolumn{9}{|c|}{$\begin{array}{l}\text { Werk- of pauzetijden aangepast om kans op RSI } \\
\text { te verminderen? }\end{array}$} \\
\hline $\mathrm{Ja}$ & & 8 & 10 & $5 \#$ & 12 & $3 \#$ & 8 & 7 \\
\hline Nee, maar is ook niet nodig & & 80 & 77 & 83 & 70 & 89 & 69 & 84 \\
\hline Nee, maar is wel behoefte aan & & 12 & 13 & 12 & 18 & $8 \#$ & 23 & $9 \#$ \\
\hline \multicolumn{9}{|c|}{$\begin{array}{l}\text { Inrichting werkplek aangepast voor goede } \\
\text { werkhouding? }\end{array}$} \\
\hline $\mathrm{Ja}$ & & 35 & 42 & $31 \#$ & 51 & $23 \#$ & 33 & 36 \\
\hline Nee, maar is ook niet nodig & & 44 & 38 & 48 & 27 & $57 \#$ & 34 & 47 \# \\
\hline Nee, maar is wel behoefte aan & & 21 & 20 & 21 & 22 & 19 & 34 & $16 \#$ \\
\hline
\end{tabular}

Met een '\#' is aangegeven dat er een relevant verschil is in percentage tussen de subgroepen. Verschillen gelijk aan of groter dan $1 / 3$ van het totaalpercentage (zie kolom totaal) worden als relevant beschouwd. 







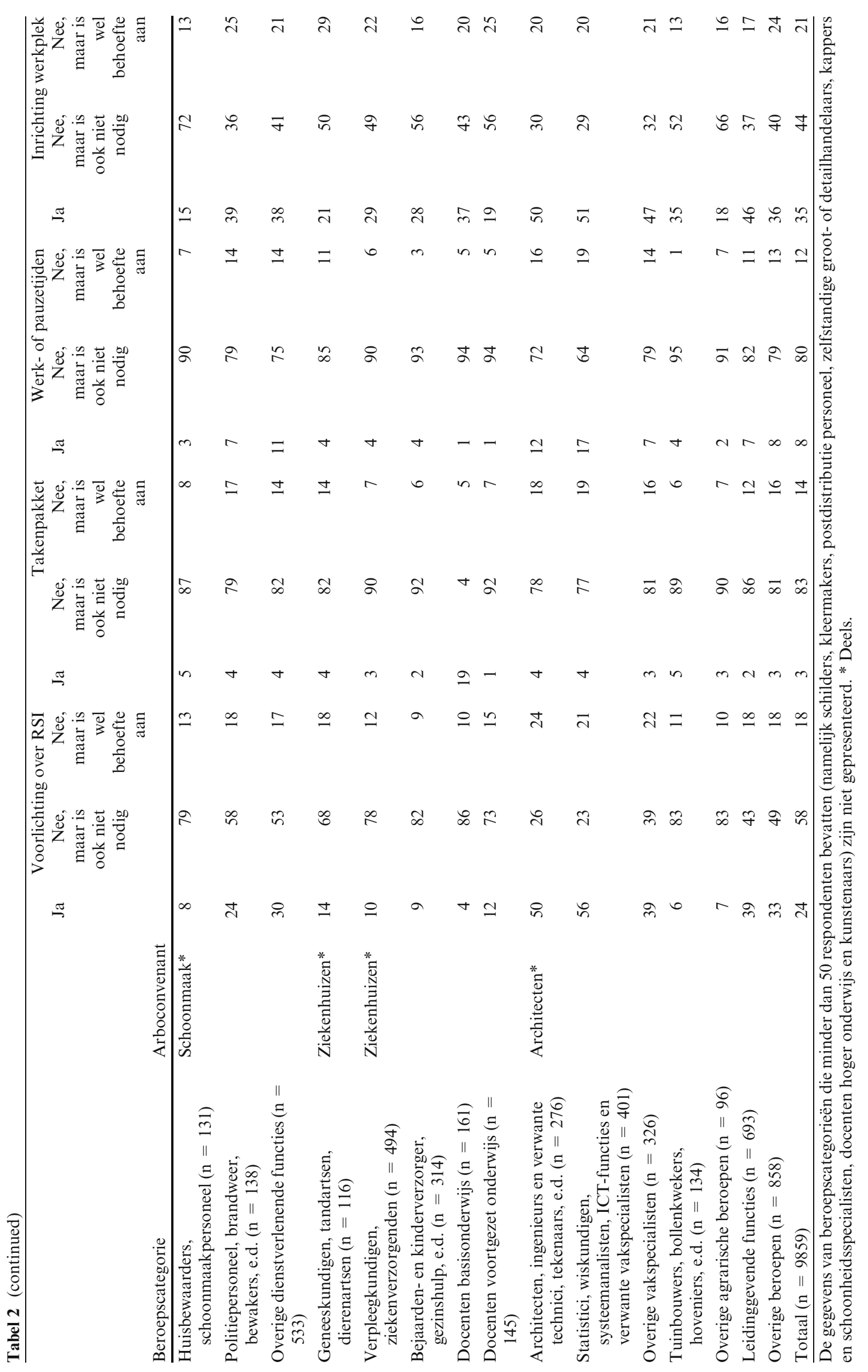












86

TBV (2005) 13:79-89

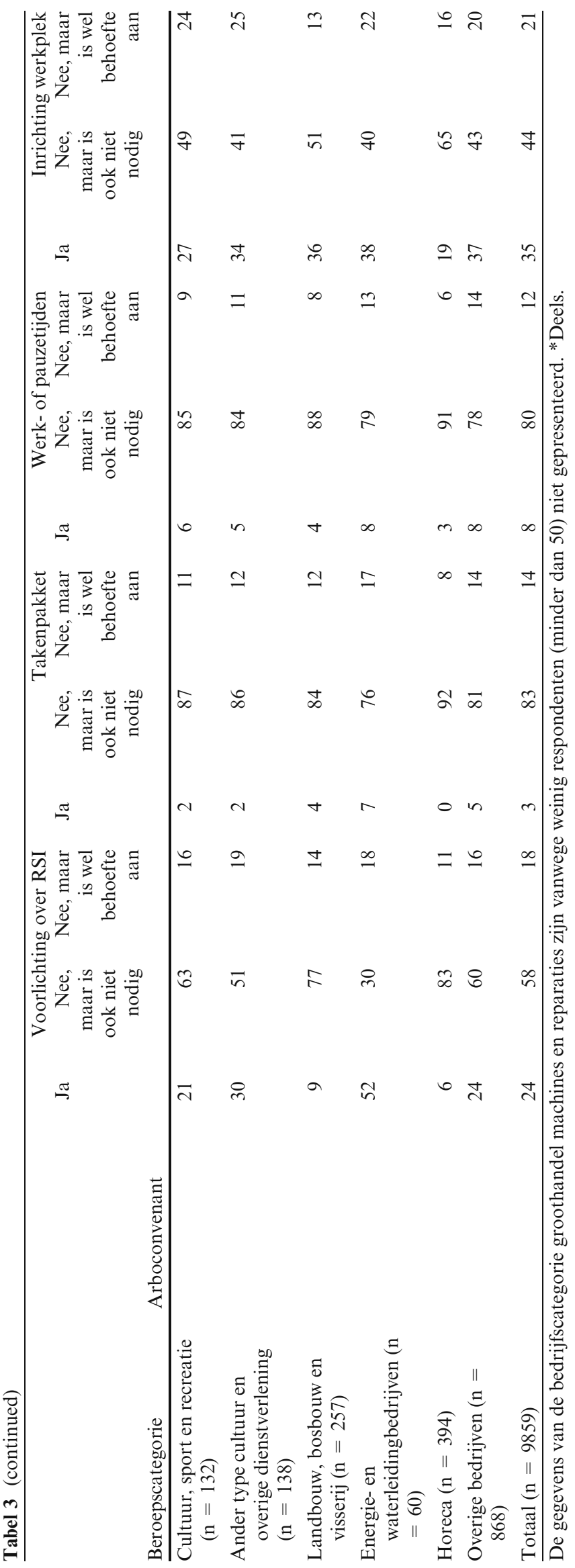

Springer 
toegepast. Werknemers hadden het meest behoefte aan 'inrichting van de werkplek' (21\%).

Bij meer werknemers van grote bedrijven dan van kleine bedrijven werden maatregelen toegepast. Daarnaast vonden meer werknemers van kleine bedrijven voorlichting niet nodig $(66 \%)$, dan werknemers van grote bedrijven $(45 \%)$.

Tussen kantoorwerkers en niet-kantoorwerkers bestonden grote verschillen in toegepaste en gewenste voorlichting. Zo ontvingen veel meer kantoorwerkers dan niet-kantoorwerkers voorlichting (respectievelijk $44 \%$ en $9 \%$ ). Meer niet-kantoorwerkers dan kantoorwerkers gaven echter aan dat zij voorlichting niet nodig vonden. De werkplek werd vooral bij kantoorwerkers aangepast. Veel niet-kantoorwerkers vonden het ook niet belangrijk dat hun werkplek werd aangepast (57\%).

Werknemers met en zonder RSI-klachten verschilden vooral bij de behoefte aan maatregelen. Werknemers met RSI-klachten hadden duidelijk meer behoefte aan maatregelen dan werknemers zonder RSI-klachten.

In tabel 2 en 3 zijn gegevens gepresenteerd over maatregelen die genomen zijn en de behoefte aan maatregelen in de verschillende beroeps- en bedrijfscategorieën. We hebben ervoor gekozen om ons in de beschrijving te richten op sectoren waarvoor een arboconvenant is afgesloten en waarbij het arboconvenant duidelijk te koppelen was aan een beroeps- of bedrijfscategorie. In de navolgende tekst gaan we allereerst in op sectoren waar binnen al veel maatregelen werden uitgevoerd, tot slot bespreken we de sectoren waar tot nu toe weinig maatregelen werden uitgevoerd. Ter illustratie hebben we ook de 'Plannen van aanpak' van de arboconvenanten bekeken om een vergelijking te kunnen maken tussen de kwantitatieve gegevens uit de NEA en de vermelde afspraken in de 'Plannen van aanpak'.

Binnen de bedrijfscategorie 'bankwezen' gaf $71 \%$ van de werknemers aan dat ze voorlichting hadden gehad en $64 \%$ gaf aan dat hun werkplek was aangepast. Veel werknemers in deze bedrijfscategorie gaven aan dat hun werkof pauzetijden waren aangepast, $30 \%$ ten opzichte van $8 \%$ in de totale onderzoekspopulatie (significant verschillend). De vele maatregelen die genomen waren, zijn mogelijk te danken aan het 'Arboconvenant Bankwezen'.

Van alle werknemers bij een ministerie gaf bijna driekwart aan dat er voorlichting was gegeven en ruim $60 \%$ dat de werkplek was aangepast. Bij $21 \%$ van deze werknemers was aandacht besteed aan aanpassing van werkof pauzetijden. Dat percentage was significant hoger dan de $8 \%$ in de totale onderzoekspopulatie. Dit zou het gevolg kunnen zijn van het Arboconvenant Rijksoverheid, waarin werd afgesproken om alle kantoorwerkplekken te voorzien van pauzesoftware.
Bij 50\% van de architecten en ingenieurs was voorlichting gegeven en bij $60 \%$ was de inrichting van de werkplek aangepast. Beide percentages waren significant hoger dan de percentages in de totale onderzoekspopulatie $(24 \%$ en $35 \%)$. Het takenpakket was bij bijna niemand uit deze sector aangepast en werken pauzetijden bij slechts 1 op de 10 werknemers. Dit kwam overeen met gegevens uit de totale onderzoekspopulatie (respectievelijk 3\% en $8 \%$ ).

Van de werknemers van gemeenten en provincies gaf $47 \%$ aan dat er voorlichting was gegeven en $53 \%$ dat de inrichting van hun werkplek was aangepast. Binnen de arboconvenanten Gemeenten en Provincies werd afgesproken dat in ieder geval aandacht moest worden besteed aan 'voorlichting', 'goed ingestelde werkplekken' en 'taakafwisseling en pauzes'.

Binnen de bedrijfscategorie 'ziekenhuizen' werden voornamelijk maatregelen getroffen ten aanzien van de inrichting van werkplek (29\%) en voorlichting $(21 \%)$. Zowel 'aanpassing van werk- of pauzetijden' $(5 \%)$ als 'inrichting van de werkplek' $(29 \%)$ werden in deze bedrijfscategorie significant minder toegepast dan in de totale onderzoekspopulatie.

Binnen de groep drukkers liep het aantal werknemers waarbij de werkplek was veranderd $(29 \%)$ of die voorlichting hadden gehad $(19 \%)$ achter bij het percentage in de totale onderzoekspopulatie. Dit verschil was door de relatief kleine groep drukkers $(n=78)$ niet significant. Binnen deze beroepscategorie was de behoefte aan een aangepaste werkplek (36\%) significant groter dan in de totale onderzoekspopulatie (21\%).

\section{Discussie}

Methodologische aandachtspunten

In de NEA zijn vier vragen gesteld over RSI-maatregelen, terwijl er meer maatregelen te bedenken zijn, bijvoorbeeld oefeningen bij een bedrijfsfysiotherapeut. Om de lengte van de vragenlijst binnen acceptabele grenzen te houden zijn bewust alleen de meest voorkomende maatregelen nagevraagd. Het kan zijn dat we bij de huidige gegevens een aantal maatregelen missen, maar wij verwachten niet dat de conclusies hierdoor beïnvloed zijn.

Het is lastig om arboconvenanten te koppelen aan specifieke beroeps- of bedrijfscategorieën. Arboconvenanten omvatten vaak meerdere beroeps- of bedrijfscategorieën en de huidige indeling sluit hier niet goed op aan. Zo zal een gedeelte van de werknemers uit de bedrijfscategorie voeding- en genotmiddelenindustrie wel onder het Arboconvenant Vleesindustrie vallen en een gedeelte van de werknemers uit deze bedrijfscategorie 
niet. Daarom brengen we uitspraken rondom arboconvenanten met enige voorzichtigheid en richten we ons op arboconvenanten die duidelijk te koppelen zijn.

Een ander punt is of werknemers correct kunnen aangeven binnen welke beroeps- en bedrijfscategorie ze vallen. De ervaring leert dat het voor sommige werknemers lastig is hun beroep binnen een bepaalde beroeps- en bedrijfscategorie te plaatsen, waardoor bij enkele beroepen misclassificatie zou kunnen zijn opgetreden. Aangezien over het algemeen de beroepen en sectoren helder gedefinieerd zijn verwachten wij niet dat de resultaten in hoofdlijnen vertekend zullen zijn door misclassificatie.

Bij drie van de vier vragen over maatregelen is de term RSI expliciet genoemd in de vraagstelling. Mogelijk associëren niet-kantoorwerkers de term RSI onterecht alleen met kantoorwerk en beantwoorden zij deze vragen anders dan wanneer de term 'klachten aan arm, nek of schouders' was gebruikt. Hierdoor kan er bij de deelpopulatie niet-kantoorwerkers een onderschatting zijn opgetreden van het aantal genomen maatregelen en de behoefte aan maatregelen. Bij de interpretatie van de tabellen dient daar rekening mee te worden gehouden.

Tot slot willen we aangeven dat vanwege het crosssectionele design van het onderzoek geen oorzaakgevolgrelaties kunnen worden aangetoond. Hierdoor was het onmogelijk om de effectiviteit van de verschillende RSImaatregelen te bepalen. Een recent onderzoek geeft wel informatie over de effectiviteit van verschillende RSI-maatregelen. ${ }^{6}$ Hierin is geconcludeerd dat geen enkele maatregel ter preventie van RSI als bewezen effectief kan worden gekwalificeerd. Wel heeft de projectgroep van dit onderzoek een top drie van veelbelovende preventieve maatregelen geformuleerd, te weten:

1. aanpassing van werk- of pauzetijden;

2. inrichting van de werkplek, en

3. verandering van takenpakket.

Verder concludeerde de projectgroep dat er matig bewijs is dat ergonomische instructies en werkaanpassingen bij werknemers met RSI-klachten geen effect hebben. Ook wat betreft de effecten op werkverzuim is voor geen enkele interventie een sterk bewijs. Onvoldoende goed onderzoek is de oorzaak van het gebrek aan bewijs en verder onderzoek op dit terrein is wenselijk. ${ }^{6}$

\section{Vergelijking met arboconvenanten}

Na de data-analyse hebben we alle 'Plannen van aanpak' behorende bij de desbetreffende arboconvenanten bestudeerd om een vergelijking te maken tussen de kwantitatieve gegevens uit de NEA en de afspraken vermeld in de 'Plannen van aanpak'. Bij deze vergelijking moet rekening worden gehouden met het feit dat in de sectoren waar arboconvenanten zijn afgesloten, wellicht al maatregelen waren genomen voordat sprake was van een arboconvenant. Een oorzaak-gevolgrelatie is dus niet aan te geven. Uit de bestudering bleek dat in een deel van de sectoren met kantoorwerkers aandacht is voor de aanschaf en verbetering van materialen zoals zit/statafels en dynamische kantoorstoelen. Maatregelen die te maken hebben met de werkplekinrichting, krijgen in een zeer groot deel van de sectoren met kantoorwerk aandacht. Bovendien is er in de sectoren waarin geen kantoorwerk wordt uitgevoerd, aandacht voor de aanschaf van betere apparatuur en materialen. In een groot aantal 'Plannen van aanpak' worden maatregelen vermeld die te maken hebben met aanpassing van werktaken en werkprocessen. Tevens worden veel maatregelen vermeld rondom werkrusttijden en overal is afgesproken om aandacht te besteden aan voorlichting. De resultaten uit de bestudering van de 'Plannen van aanpak' komen grotendeels overeen met bevindingen uit het huidige onderzoek.

\section{Conclusie}

In 2003 werden de RSI-maatregelen 'inrichting van de werkplek' en 'voorlichting' het meest toegepast, respectievelijk bij $35 \%$ en $24 \%$ van de werknemers. Daarnaast hadden werknemers de meeste behoefte aan 'inrichting van de werkplek' $(21 \%)$. Maatregelen met betrekking tot 'verandering van takenpakket' en ten aanzien van 'werkof pauzetijden' werden slechts beperkt toegepast. Een logische verklaring is dat deze maatregelen lastiger te implementeren zijn doordat hiervoor organisatorische veranderingen nodig zijn. Ook financiële redenen en tijdsaspecten kunnen meespelen. Tussen sectoren waren duidelijke verschillen in RSI-maatregelen die al toegepast werden en RSI-maatregelen waar nog behoefte aan was. Deze verschillen zijn mogelijkerwijs te verklaren door afgesloten arboconvenanten.

\section{Literatuur}

Heinrich J, Blatter BM. RSI-klachten in de Nederlandse beroepsbevolking. Trends, risicofactoren en verklaringen. TSG 2005; 83: $16-24$.

Hoogervorst JH. Arboconvenanten nieuwe stijl: beleidsstrategie voor de komende vier jaar (1999-2002). Tweede Kamer, vergaderjaar 1998-1999, 26 375, nr. 1.

Gezondheidsraad. RSI. Publicatienummer 2000/22. Den Haag: Gezondheidsraad, 2000.

Bossche SNJ van den, Smulders PGW. De Nationale Enquête Arbeidsomstandigheden 2003: Methodologie en globale resultaten. Hoofddorp: TNO Arbeid, 2004. 
Broersen JPJ, Fortuin RJ, Dijkstra L et al. Monitor Arboconvenanten: kengetallen en grenswaarden. Tijdschr Bedrijfs Verzekeringsgeneeskd 2004; 12: 100-104.

Blatter BM, Bongers PM, Dieën JH van et al. RSI maatregelen: preventie, behandeling en reïntegratie. Programmeringstudie in opdracht van de ministeries van Sociale Zaken en Werkgelegenheid en van Volksgezondheid, Welzijn en Sport. Den Haag: ministerie van SZW, 2004, ISBN 905901488 x. 